\title{
Incisional hernia recurrence through genomic profiling: a pilot study
}

\author{
R. Calaluce • J. W. Davis $\cdot$ S. L. Bachman • \\ M. M. Gubin · J. A. Brown · J. D. Magee • \\ T. S. Loy $\cdot$ B. J. Ramshaw $\cdot$ U. Atasoy
}

Received: 29 January 2011/ Accepted: 11 May 2012/Published online: 31 May 2012

(C) The Author(s) 2012. This article is published with open access at Springerlink.com

\begin{abstract}
Purpose Although situational risk factors for incisional hernia formation are known, the methods used to determine who would be most susceptible to develop one are unreliable. We hypothesized that patients with recurrent incisional hernias may possess unique gene expression profiles. Methods Skin and intact fascia were collected from 15 normal control (NC) patients with no hernia history and 18 patients presenting for recurrent incisional hernia $(\mathrm{RH})$ repair. Microarray analysis was performed using whole genome microarray chips on NC $(n=8)$ and RH $(n=9)$.
\end{abstract}

Electronic supplementary material The online version of this article (doi:10.1007/s10029-012-0923-4) contains supplementary material, which is available to authorized users.

R. Calaluce · S. L. Bachman · M. M. Gubin ·

J. A. Brown · J. D. Magee · U. Atasoy $(\bowtie)$

Department of Surgery, The University of Missouri Health

Sciences Center, University of Missouri, One Hospital Drive,

M610C, Columbia, MO 65212, USA

e-mail: atasoyu@missouri.edu

R. Calaluce

e-mail: calalucer@health.missouri.edu

S. L. Bachman

e-mail: bachmans@health.missouri.edu

M. M. Gubin

e-mail: mmgc47@mail.missouri.edu

J. A. Brown

e-mail: brownjul@health.missouri.edu

J. D. Magee

e-mail: mageejd@health.missouri.edu

J. W. Davis

Department of Health Management and Informatics,

The University of Missouri Health Sciences Center,

University of Missouri, Columbia, MO, USA

e-mail: davisjwa@health.missouri.edu
These samples were further investigated using a pathwayspecific PCR array containing fibrosis-related genes.

Results Microarray data revealed distinct differences in the gene expression profiles between $\mathrm{RH}$ and $\mathrm{NC}$ patients. One hundred and sixty-seven genes in the skin and 7 genes in the fascia were differentially expressed, including 8 directly involved in collagen synthesis. In particular, GREMLIN1, or bone morphogenetic protein antagonist 1, was under expressed in skin (fold $=0.49, p<10^{-7}$, $q=0.0009$ ) and fascia (fold $=0.23, \quad p<10^{-4}$, $q=0.095)$ of RH patients compared with NC. The PCR array data supported previous reports of decreased collagen $\mathrm{I} / \mathrm{III}$ ratios in skin of RH versus $\mathrm{NC}$ (mean $=1.51 \pm 0.73$ vs. mean $=2.26 \pm 0.99$; one-sided $t$ test, $p=0.058$ ).

\section{J. W. Davis}

Department of Statistics, University of Missouri,

Columbia, MO, USA

\section{M. Gubin · U. Atasoy}

Department of Molecular Microbiology and Immunology,

University of Missouri, Columbia, MO, USA

T. S. Loy

Department of Pathology, Ross University, Roseau,

Dominican Republic

e-mail: tloy@ rossmed.edu.dm

B. J. Ramshaw

Transformative Care Institute, Daytona Beach, FL, USA

e-mail: bramshaw98@yahoo.com

U. Atasoy

Department of Child Health, University of Missouri,

Columbia, MO, USA 
Conclusion To our knowledge, this is the first microarray-based analysis to show distinct gene expression profiles between the skin and fascia of $\mathrm{RH}$ and NC patients and the first report of an association between GREMLIN1 and incisional hernia formation. Our results suggest that gene expression profiles may act as surrogate markers that stratify patients into different groups at risk for hernia development prior to their initial surgery.

Keywords Ventral hernia - Recurrence - Microarray · GREM1 - Gene expression · Collagen I/III ratio

$\begin{array}{ll}\text { Abbreviations } \\ \text { RT-PCR } & \begin{array}{l}\text { Reverse-transcriptase polymerase chain } \\ \text { reaction }\end{array} \\ C_{\mathrm{t}} & \text { Cycle threshold } \\ \text { cDNA } & \text { Complementary DNA } \\ \text { UNG } & \text { Uracil- } N \text {-glycosylase } \\ \text { IRB } & \text { Institutional review board } \\ \text { OR } & \text { Odds ratio } \\ \text { GO } & \text { Gene ontology } \\ \text { RIN } & \text { RNA integrity number }\end{array}$

\section{Introduction}

Incisional hernia repair comprises a significant proportion of a general surgeon's practice. The incidence of incisional hernias ranges from 2 to $11 \%$, with a substantial recurrence rate reported between 10 and $50 \%$ [1]. Based upon this estimate, 100,000 incisional hernia repairs are predicted to be performed each year costing $\$ 2.5$ billion [1]. While recurrence rates have decreased by using prosthetic mesh in the repair, a significant number of patients develop multiple recurrences with estimates in the literature ranging from 5 to $20 \%$ [2].

Several risk factors for developing incisional hernias have been identified including wound infection, abdominal distention, pulmonary complications, male gender, age, and obesity [1]. Although risk factors for recurrent incisional hernias have also been evaluated, the literature is controversial with regard to many of these, such as body mass index, ascites, large hernias exceeding $10 \mathrm{~cm}$ in width or length, continued smoking, occupational lifting, and woundhealing disorders (e.g., hematoma, seroma, infection) [1].

Current data suggest that incisional hernias are commonly caused by failure of early surgical wound healing [3]. Since collagen I provides tensile strength to connective tissue, and immature collagen III found in early wounds is weaker, investigations into the collagen I-to-III ratio have demonstrated a decreased ratio in patients with direct and indirect hernias as compared with controls [4, 5]. This decrease in the collagen I/III ratio was attributed to the relative increase in collagen III synthesis and was also seen in incisional hernias $[4,6]$. Moreover, a decreased collagen I/III ratio in incisional hernias supports the possibility of a high-risk group more susceptible to hernia formation [7]. White and colleagues performed a preliminary immunohistochemical trial examining the skin and fascia of 16 incisional hernia patients for collagen I and III and compared the ratio to normal foregut collected from bariatric patients [8]. They found a significant decrease in the ratio in the skin of the hernia patients but found no difference in the fascia [8].

While patients with collagen and connective tissue diseases, such as Ehlers-Danlos syndrome, osteogenesis imperfecta, and Marfan's syndrome, are known to form hernias, there are no data on potential genetic predispositions to hernia formation in otherwise normal patients [9-11]. We hypothesized that recurrent incisional hernia formation may be due to subtle differences in gene expression (mRNA) profiles that ultimately alter wound healing. We designed a pilot study comparing the skin and fascia from recurrent hernia (RH) patients to those who underwent laparoscopic cholecystectomy (normal control, NC) in order to identify distinct genomic profiles in the two patient populations.

\section{Methods}

Patient samples and tissue acquisition

After obtaining IRB approval and receiving appropriate informed consent, 33 patients participated in this study. Patients were eligible if they were 18 years of age or older and underwent laparoscopic repair of a recurrent ventral or incisional hernia. Patients were excluded if they were under 18; had a history of steroid use, severe COPD, pulmonary, or connective tissue disorders; or were prisoners. Eighteen patients with at least one recurrent incisional hernia presented for laparoscopic incisional hernia repair. The designated controls were 15 healthy patients who had no hernia history and underwent laparoscopic cholecystectomy. Approximately $1 \mathrm{~cm}^{2}$ of skin and fascia was removed from the trocar placement site, remote from the hernia or old incisions. The tissue samples were divided and placed in either $10 \%$ buffered formalin or RNALat$\mathrm{er}^{\mathrm{TM}}$ RNA Stabilization Reagent (Qiagen, Valencia, CA). Tissue was stored in RNALater ${ }^{\mathrm{TM}}$ for up to $48 \mathrm{~h}$ at room temperature. Approximately $100-150 \mathrm{mg}$ of tissue was used for RNA isolation.

RNA isolation and RNA amplification

Total RNA was isolated from the skin and fascia specimens by following the manufacturer's protocol from the 
RNeasy ${ }^{\circledR}$ Lipid Tissue Mini Kit (Qiagen) using a rotor homogenizer and on-column DNase treatment. Total RNA was amplified using the WT-Ovation ${ }^{\mathrm{TM}}$ Pico RNA Amplification System protocol (NuGen, San Carlos, CA) as previously described $[12,13]$.

cDNA labeling, RNA quantity and quality, and microarray

Of the 33 enrolled patients, $8 \mathrm{NC}$ and $9 \mathrm{RH}$ patients were selected for microarray analysis based on the quantity, quality, and integrity of the RNA. For each skin and fascia sample, $1.5 \mu \mathrm{g}$ biotin labeled, amplified cDNA was hybridized to a Sentrix ${ }^{\circledR}$ Human-6 v.2 Whole Genome Expession BeadChips (Sentrix Human WG-6; Illumina, San Diego, CA) as previously described [13].

\section{Validation by quantitative RT-PCR (qPCR) and PCR array}

cDNA was generated from $10 \mathrm{ng}$ of the same total RNA samples as used for the microarray experiment (15 patients analyzed by microarray with sufficient amounts of remaining high-quality RNA) and SuperScript ${ }^{\mathrm{TM}}$ III Platinum ${ }^{\circledR}$ TwoStep qPCR Kit with SYBR ${ }^{\circledR}$ Green (Invitrogen Carlsbad, CA). For COL1A and GREM1, qPCR was performed on the StepOne ${ }^{\mathrm{TM}}$ Real-Time PCR System (Applied Biosystems, Foster City, CA) using GAPDH as a reference gene as previously described [13]. A PCR array, focusing on the expression of 84 key genes related to dysregulated tissue remodeling during wound healing, was also performed on these 15 patients by Global Biologics (Columbia, MO). Briefly, RNA quantity and purity were assessed using NanoDrop ND-2000 (Nanodrop Technologies, Wilmington, DE, USA). RNA integrity was evaluated using the RNA integrity algorithm generated by the Bioanalyzer 2100 with the Eukaryotic RNA Pico Series II reagents (Agilent Technologies, Santa Clara, CA, USA). RIN values ranged from 5 to 8 . RNA was reverse transcribed with the RT ${ }^{2}$ First Strand cDNA kit (SABiosciences, Frederick, MD), and qPCR was performed using the Human Fibrosis RT $^{2}$ Profiler $^{\text {TM }}$ PCR Array System (SABiosciences, Frederick, MD) and the Roche LightCycler480 instrument. As part of the qPCR quality assessment process, each sample was evaluated for the presence of genomic cDNA contamination, followed by three positive PCR and three reverse transcriptase controls. The chosen housekeeping or reference gene, RPL13A, was selected from a panel of five housekeeping genes on the array based on the most uniform expression range across all samples. GREM1 and COLIA qPCR data were statistically compared using a two-sample $t$ test on the $\Delta C_{\mathrm{t}}$ values. The PCR array data were compared between groups using a moderated $t$ test on the $\Delta C_{\mathrm{t}}$ values as long as the gene was considered to be reliably expressed $\left(C_{\mathrm{t}}<35\right.$ in $75 \%$ of samples) [14].

Immunohistochemistry

Specimens were fixed in $10 \%$ buffered formalin, routinely processed, embedded in paraffin, and cut at $4 \mu \mathrm{m}$. Immunohistochemistry was performed using the automated horseradish peroxidase Autostainer/Envision Plus method (Dakocytomation, Carpenteria, CA) as previously described $[15,16]$.

Statistical analysis of microarray data

Analysis of microarray gene expression data was primarily performed using $\mathrm{R}$ open-source software (R Foundation, Vienna, Austria). Any genes considered "not detectable" (Illumina software detection $<1 \%$ ) across $>50 \%$ of patient samples were excluded from further statistical analyses in order to reduce false positives. Nonspecific filtering was also carried out to remove genes with little variability as previously described [17]. Differential gene expression analysis was performed using a moderated $t$ statistics applied to the $\log _{2^{-}}$ transformed normalized intensity for each gene using an empirical Bayes approach [14]. Adjustment for multiple testing was made using the false discovery rate method of Benjamini and Hochberg with a significance cutoff of $q<30 \%$ [18], since the list of discovered genes was relatively small. We declared a gene differentially expressed if it was statistically significant after adjusting for multiple testing and had a fold change $\geq 1.5$ (either over- or under expressed).

Gene ontology (GO) analyses were conducted on the resulting list of significantly different genes to test their association with independently established GO terms to shed insight on the common functions of the differentially identified genes. We carried out GO analyses for overrepresentation of biologic process, molecular function, and cellular component ontologies, which generated an odds ratio (OR) and $p$ value for each GO category, using methods previously described [13]. A small $p$ value $(<0.05)$ and large OR indicated that the number of selected genes associated with a given term (e.g., wound healing) was larger than expected due to chance. GO categories containing less than 10 genes represented on the array were not considered to be statistically reliable indicators and were not reported even if significant.

\section{Results}

Demographics

Demographics for the 33 enrolled patients and the subset of 17 patients whose samples were analyzed by microarray 
are shown in Table 1. The majority (26/33) of enrolled patients were female, and all but one sample analyzed by microarray were from females. The $\mathrm{RH}$ and $\mathrm{NC}$ groups analyzed by microarray were comparable $(p>0.05)$ on all demographics except diabetes $(p=0.03)$ and previous surgery $(p=0.01)$, neither of which is unexpected in these populations.

Identification of differential gene expression in the skin and fascia of RH patients via microarray

Illumina microarray data revealed that 142 complete genes and 25 expressed sequence tags (ESTs) for a total of 167 genes were differentially expressed in the skin, and 6 complete genes and 1 EST were differentially expressed in fascia for a total of 7 genes. While the full results are included in Online Resources 1 and 2, a representative list of genes is reported in Tables 2 and 3. These were selected based on our interest in hernia formation and wound healing, as well as regulation of transcription and immunology.

Eight discovered genes were directly involved in collagen synthesis (PCOLCE2, CTHRC1, COL1A1, COL3A1, COLAA1, COL5A1, COL5A2, and COL6A3). Moreover, as supported by the literature, several have been associated with hernia formation, Ehlers-Danlos syndrome, and Marfan's syndrome (e.g., COL1A1, COL3A1, COL5A1, $F B N 1$, and TIMPI).

A novel and unexpected gene found to be statistically significant in both the skin and fascia was GREMLIN1 (GREM1, also known as cysteine knot superfamily 1, BMP Antagonist 1, CKTSF1B1; induced in high glucose 2, IHG-2; and down regulated by $v$-mos, DRM) [19]. In fascia, GREMI had a fold change of $0.23\left(q=0.095, p<10^{-4}\right)$, while in skin, it was found to have a fold change of $0.49(q=0.0009$, $p<10^{-7}$ ). GREMI was under expressed in both the skin and fascia of RH patients in comparison with NC.

Gene ontology analysis of differentially expressed genes

Gene ontology analyses were performed to determine whether there were common functions or descriptive terms that were statistically abundant in the list of differentially expressed genes, as quantified by odds ratios. Although the fascia gene list was too sparse for analysis, in skin we found more than 53 biologic process (BP) enriched terms, 18 enriched molecular function (MF) terms, and 10 cellular component (CC) terms (Online Resources 3, 4, and 5).

Table 4 represents a sample of important biologic processes that we found to be differentially enriched in skin. For example, in the skin of RH patients, many differentially expressed genes were found to be more abundant than expected in biologic processes such as: response to wounding; regulation of immune response; activation of plasma proteins during acute inflammatory response; lipid metabolic process; multicellular organismal development; and cell adhesion. Moreover, these analyses illustrate that many genes such as the collagen genes have diverse functions and appear in several BP categories. For instance, COL3AI and $F B N 1$ were associated with response to wound healing, blood coagulation, regulation of body fluids, as well as organ development. COL3Al was also associated with regulation of immune response, regulation of multicellular organismal process, negative regulation of response to stimulus, cell-matrix adhesion, and negative regulation of immune system process.

\section{Validation of gene expression by qPCR and PCR array}

Based upon the Illumina microarray results, COL1A1 and GREM1 were selected for validation by qPCR. COL1A1 was overexpressed (2.33 fold) in the skin of $\mathrm{RH}$ patients as compared to $\mathrm{NC}$, but was under expressed ( 0.34 fold) in the fascia. GREM1 was under expressed in both the skin (2.6 fold) and fascia (11.2 fold) of RH patients in comparison with NC (Online Resource 6). In order to explore the relationship between other relevant wound-healing genes, such as COL1A1 and COL3A1, a PCR array was used to measure gene expression on a subset of 15 remaining patient samples. Eighty genes on the PCR array were reliably expressed and were analyzed for differences. The PCR array results confirmed the microarray data as illustrated by the strong agreement of fold change (Pearson $r=0.74, p<10^{-7}$ ) among the 39 genes common to both arrays which were detectable (Fig. 1). The 22 genes with
Table 1 Demographics of enrolled patients and the subset analyzed by microarray

\begin{tabular}{|c|c|c|c|c|c|c|}
\hline \multirow[t]{2}{*}{ Characteristics } & \multicolumn{3}{|c|}{ Patients enrolled } & \multicolumn{3}{|c|}{ Patients analyzed by microarray } \\
\hline & $\mathrm{RH}(n=18)$ & $\mathrm{NC}(n=15)$ & $p$ & $\mathrm{RH}(n=9)$ & $\mathrm{NC}(n=8)$ & $p$ \\
\hline $\operatorname{Sex}(M / F)$ & $4 / 14$ & $3 / 12$ & 0.99 & $0 / 9$ & $1 / 7$ & 0.47 \\
\hline Age & 553.2 & 44.9 & 0.14 & 50.9 & 39.1 & 0.23 \\
\hline BMI & 36.6 & 30.5 & 0.03 & 39.2 & 31.4 & 0.10 \\
\hline Smoker & 8 & 2 & 0.07 & 4 & 2 & 0.62 \\
\hline Diabetes & 7 & 0 & 0.01 & 5 & 0 & 0.03 \\
\hline Previous surgery & 18 & 6 & 0.01 & 9 & 3 & 0.01 \\
\hline
\end{tabular}


Table 2 Selected genes from skin of RH patients significantly over- or under expressed in comparison with skin from NC, in ascending order of fold change $(\mathrm{NC} / \mathrm{RH})$

\begin{tabular}{|c|c|c|}
\hline Gene symbol & Fold change & Gene name \\
\hline GREM1 & 0.49 & Gremlin 1, cysteine knot superfamily, homolog (Xenopus laevis) \\
\hline TP63 & 0.5 & Tumor protein p63 \\
\hline KRT15 & 0.53 & Keratin 15 \\
\hline$T F A P 2 C$ & 0.59 & Transcription factor AP-2 gamma (activating enhancer binding protein 2 gamma) \\
\hline$K L F 5$ & 0.63 & Kruppel-like factor 5 (intestinal) \\
\hline ELL2 & 0.66 & Elongation factor, RNA polymerase II, 2 \\
\hline NAP1L1 & 0.66 & Nucleosome assembly protein 1 -like 1 \\
\hline COL5A2 & 1.51 & Collagen, type $\mathrm{V}$, alpha 2 \\
\hline$P D X K$ & 1.51 & Pyridoxal (pyridoxine, vitamin B6) kinase \\
\hline GHR & 1.54 & Growth hormone receptor \\
\hline$N U C B 1$ & 1.55 & Nucleobindin 1 \\
\hline$C D 81$ & 1.56 & CD81 molecule \\
\hline RBPMS2 & 1.59 & RNA binding protein with multiple splicing 2 \\
\hline TIMP1 & 1.59 & TIMP metallopeptidase inhibitor 1 \\
\hline ANXA5 & 1.59 & Annexin A5 \\
\hline CAVI & 1.60 & Caveolin 1, caveolae protein, $22 \mathrm{kDa}$ \\
\hline THY1 & 1.62 & Thy- 1 cell surface antigen \\
\hline$P M P 22$ & 1.62 & Peripheral myelin protein 22 \\
\hline COL5A1 & 1.63 & Collagen, type V, alpha 1 \\
\hline FBLN1 & 1.63 & Fibulin 1 \\
\hline FBN1 & 1.63 & Fibrillin 1 \\
\hline CLDN5 & 1.66 & Claudin 5 (transmembrane protein deleted in velocardiofacial syndrome) \\
\hline MSX1 & 1.66 & Msh homeobox 1 \\
\hline COL1A2 & 1.69 & Collagen, type I, alpha 2 \\
\hline$P D G F R B$ & 1.7 & Platelet-derived growth factor receptor, beta polypeptide \\
\hline FAP & 1.74 & Fibroblast activation protein, alpha \\
\hline$D C N$ & 1.74 & Decorin \\
\hline MCAM & 1.79 & Melanoma cell adhesion molecule \\
\hline COL6A3 & 1.8 & Collagen, type VI, alpha 3 \\
\hline CILP & 1.99 & Cartilage intermediate layer protein, nucleotide pyrophosphohydrolase \\
\hline$L U M$ & 2.03 & Lumican \\
\hline COL1A1 & 2.05 & Collagen, type I, alpha 1 \\
\hline FZD4 & 2.11 & Frizzled homolog 4 (Drosophila) \\
\hline CTHRC1 & 2.17 & Collagen triple helix repeat containing 1 \\
\hline HSPB6 & 2.17 & Heat shock protein, alpha-crystallin-related, B6 \\
\hline$R B P 4$ & 2.17 & Retinol binding protein 4 , plasma \\
\hline COL3A1 & 2.3 & Collagen, type III, alpha 1 \\
\hline COLAA1 & 2.43 & Collagen, type IV, alpha 1 \\
\hline ANGPTL2 & 2.7 & Angiopoietin-like 2 \\
\hline CD36 & 3.07 & CD36 molecule (thrombospondin receptor) \\
\hline FSTL1 & 3.15 & Follistatin-like 1 \\
\hline PCOLCE2 & 3.64 & Procollagen C-endopeptidase enhancer 2 \\
\hline$L E P$ & 5.03 & Leptin \\
\hline
\end{tabular}

large fold changes found by PCR array are reported in Table 5, with results for all genes on the PCR array presented in Online Resource 7. The distributions of patient expression levels from the PCR array for four selected differentially expressed genes overlap less than $50 \%$ on average (Fig. 2). 
Table 3 Selected genes from fascia of RH patients over- or under expressed in comparison with fascia from NC patients in ascending order of fold change $(\mathrm{NC} / \mathrm{RH})$

\begin{tabular}{lll}
\hline Gene symbol & Fold change & Gene name \\
\hline GREM1 & 0.23 & Gremlin 1 \\
PRLR & 0.39 & Prolactin receptor \\
LEFTY & 0.43 & Left-right determination factor \\
SCRG1 & 0.44 & Scrapie responsive protein 1 \\
RNF144A & 0.49 & Ring finger protein 1 \\
PDZRN4 & 0.54 & PDZ domain containing ring finger 4 \\
\hline
\end{tabular}

COL1/COL3 ratio by microarray, PCR array, and immunohistochemistry

By microarray, COL1A1/COL3Al ratio in skin of $\mathrm{RH}$ patients was slightly lower than NC patients, but was not significant (1.33 vs. $1.46, p=0.65)$. Similar but significant results were found for COL1A2/COL3A1 (0.59 vs. 0.79, $p=0.02)$. Neither of these ratios were statistically different in the fascia. Immunohistochemistry on 5 patients demonstrated slightly greater staining intensity of COL3AI than COL1A1 in the skin and fascia from RH patients in comparison with NC. Analysis by PCR array revealed that gene expression of COL3A1 was greater than COL1A2 (the second alpha chain of the collagen 1 molecule) in skin in both groups. According to the manufacturer, COL1A2 was selected because it was referenced more often in relation to fibrosis in public data bases than COL1A1. Moreover, the ratio of COL1A2/COL3A1 was decreased in the RH group as compared to $\mathrm{NC}(1.51$ vs. $2.26, p=0.058$, one-sided $t$ test). These results agree with reports in the literature [4-12].

The gene expression ratio of COL1A2/COL3A1, in conjunction with GREM1, was explored as a means of stratifying patients into $\mathrm{NC}$ or $\mathrm{RH}$. We also considered COL1A2 and COL3A1 on their own (i.e., not in ratio form) in combination with GREM1. All pairwise combinations of these 4 markers were considered as means of classifying patients into their correct group ( $\mathrm{RH}$ or $\mathrm{NC}$ ) using quadratic discriminant analysis (QDA). QDA may be thought of as a method that yields the best curve ("separation boundary") that can be drawn in order to maximize the separation between the group means. We found that by using leave-one-out cross-validation, the combination of $\{$ GREM1, COL3A1 \} (Fig. 3) achieved the highest accuracy (86\%), followed by either $\{C O L 3 A 1, C O L 1 A 2\}$ or $\{$ COL1A2, COL1A2/COL3A1 $\}$ at $73 \%$ accuracy, and $\{$ GREM1, COL1A2 $\}$ or $\{$ GREM1, COL1A2/COL3A1 $\}$ at $66 \%$ accuracy.

\section{Discussion}

The molecular biology of hernia repair is largely unknown. Equally unclear is why incisional hernia repairs, either laparoscopic or open, frequently recur. We designed a pilot study, using microarrays, to identify potentially specific gene profiles in patients with recurrent incisional hernias $(\mathrm{RH})$. We analyzed the skin and fascia from these patients and compared them to skin and fascia taken from patients who had no history of hernias (NC).

Our study was unique both in using a genomic-based approach (microarray and PCR array) and in taking skin and fascia samples away from the site of the incisional hernia. The acquisition of skin and fascia at the start of the procedure, prior to trocar placement, allowed us to avoid the confounder of biologic and pathologic processes occurring in the hernia (e.g., inflammation, wound healing) that could skew our results. Wound infection, for instance, has been widely reported as the most significant independent prognostic factor for incisional hernia [1, 20-22]. Although technical factors such as type of repair or use of mesh have been attributed to cause recurrence, they do not explain all hernia recurrences [1]. We theorized that variations in gene expression may play a role in wound healing and recurrence.

Our experiments have shown distinct gene expression profiles between the skin and fascia of RH and NC patients. When comparing active gene expression profiles, we found

Table 4 Selected results from GO analysis of biologic processes in list of differentially expressed genes from skin samples

\begin{tabular}{|c|c|c|c|c|}
\hline GO ID & OR & $p$ & Term & Differentially expressed genes in term \\
\hline 0002541 & 7.01 & 0.039 & $\begin{array}{l}\text { Activation of plasma proteins involved in } \\
\text { acute inflammatory response }\end{array}$ & $C F D, C F H$ \\
\hline 0007160 & 6.62 & 0.001 & Cell-matrix adhesion & COL3A1, ECM2, NID1, EPDR1, THY1 \\
\hline 0050776 & 4.89 & 0.012 & Regulation of immune response & COL3A1, CFD, CFH, THY1 \\
\hline 0009611 & 3.18 & 0.001 & Response to wounding & $\begin{array}{l}\text { COL3A1, CFD, FABP4, FBN1, CFH, ANXA5, PROK2, VWF, CAV1, } \\
\quad \text { AOC } 3, C D 36\end{array}$ \\
\hline 0007155 & 2.36 & 0.007 & Cell adhesion & $\begin{array}{l}\text { FERMT2, COL5A1, COL6A3, VCAN, DPT, ISLR, LAMA4, MCAM, } \\
\text { MFAP4, S1OOA4, CLDN5, AOC3, CD36 }\end{array}$ \\
\hline
\end{tabular}

These terms are more abundant than expected and are sorted by odds ratio (OR) 


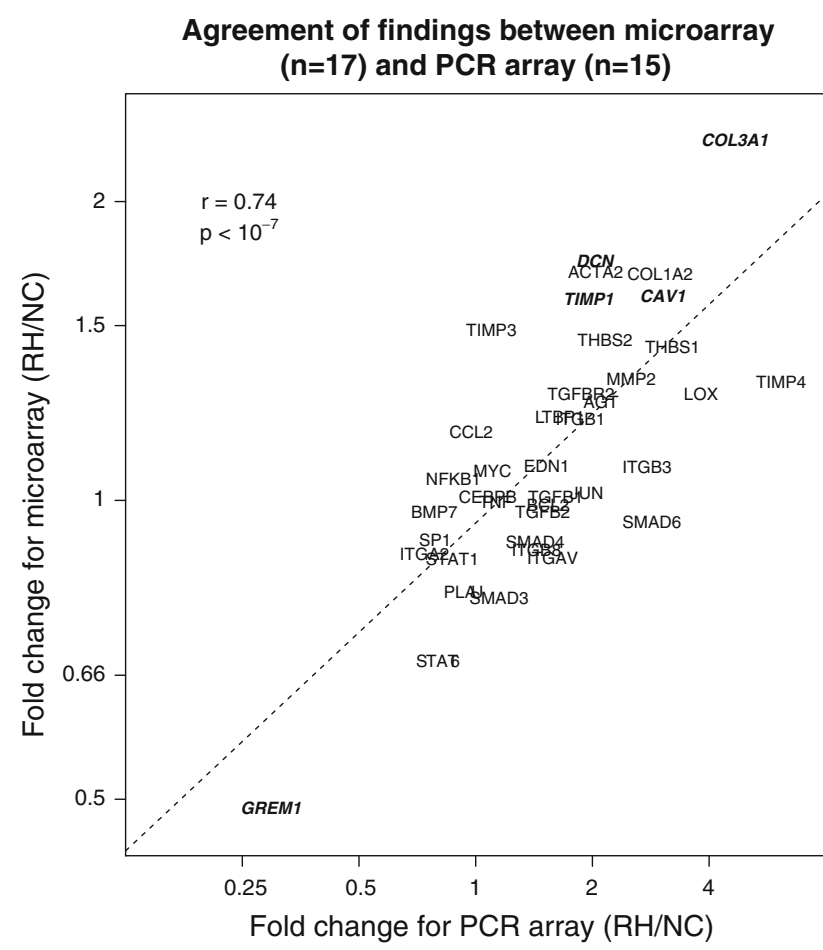

Fig. 1 Agreement of microarray and PCR array results. The genes which were detected on both the microarray and the PCR array are plotted against their fold change (RH/NC) for each platform. Bold italicized gene symbols indicate they were significantly different based on microarray data

more statistically significant genes in the skin than the fascia. We found greater variability in gene expression in fascia than skin in our samples, which is apparent graphically (Online Resources 8 and 9). Since an increase in variance reduces the power to detect differences, this is the most obvious explanation for the shorter fascia gene list. The functions of the genes in the skin were diverse and included wound healing, transcription regulation, and immunology.

The sparse number of genes in the fascia precluded GO analysis. In the skin, GO analysis further expanded these to $53 \mathrm{BP}$ functions, including regulation of the immune and inflammatory responses, organ development, and cell adhesion. GO analysis also revealed $10 \mathrm{CC}$ and $18 \mathrm{MF}$ categories, with most genes associated with the extracellular region and plasma membrane, and enzyme inhibitor activity and receptor binding, respectively. The relationship of these genes to known biologic functions can assist in our understanding of the basic science of hernia formation.

One of our most intriguing findings was altered GREMI expression in the skin and fascia of RH patients. Originally isolated from the neural crest of the Xenopus as a bone morphogenetic protein (BMP) antagonist, GREMI is an important regulator of limb development and may play a role in regulating organogenesis, body patterning, as well as tissue differentiation [19, 23, 24]. High levels have been
Table 5 Genes sorted by fold change (RH/NC) in skin by PCR array with fold changes $>2$ or $<0.5$ between RH $(n=8)$ and NC $(n=7)$, where $*$ denotes $p<0.05$

\begin{tabular}{|c|c|c|}
\hline Gene symbol & Fold change & $p$ \\
\hline GREMI* & 0.29 & 0.007 \\
\hline$A G T$ & 2.08 & 0.184 \\
\hline THBS2 & 2.11 & 0.081 \\
\hline TIMP2 & 2.29 & 0.059 \\
\hline$H G F$ & 2.32 & 0.084 \\
\hline$E N G$ & 2.37 & 0.060 \\
\hline$M M P 2$ & 2.47 & 0.054 \\
\hline$M M P 9 *$ & 2.57 & 0.037 \\
\hline$C T G F^{*}$ & 2.65 & 0.025 \\
\hline ITGB3* & 2.72 & 0.036 \\
\hline$M M P 3$ & 2.78 & 0.063 \\
\hline SMAD6* & 2.78 & 0.033 \\
\hline COL1A2* & 2.92 & 0.035 \\
\hline$C A V 1^{*}$ & 2.98 & 0.020 \\
\hline$C C L 3 *$ & 3.01 & 0.020 \\
\hline THBS1* & 3.15 & 0.012 \\
\hline SERPINE1* & 3.23 & 0.013 \\
\hline$I T G A 1^{*}$ & 3.34 & 0.010 \\
\hline$L O X^{*}$ & 3.76 & 0.006 \\
\hline COL3A1* & 4.54 & 0.002 \\
\hline$I L 10^{*}$ & 4.83 & 0.001 \\
\hline TIMP4* & 6.02 & 0.001 \\
\hline
\end{tabular}

found in nondividing and terminally differentiated cells such as neurons, alveolar epithelial cells, and goblet cells $[19,24]$. An earlier name of GREMI was $I H G-2$ because its expression in glomerular mesangial cells was induced by high glucose, mechanical strain, and TGF- $\beta$ [25]. GREM1 has been suggested to be a modulator of mesangial cell proliferation and epithelial-mesenchymal transdifferentiation in diabetes and has been shown to have increased expression in various diabetic nephropathy models as well as being involved in the pathophysiology of progressive renal fibrogenetic diseases [26, 27]. Moreover, gene and protein expression have been reported in fibroblast cultures harvested from patients diagnosed with systemic sclerosis [28].

Although GREM1 has not been associated with hernia formation or wound healing, it has been found in the stromal cells of basal cell carcinomas [29]. This group also reported a concomitant expression of FOLLISTATIN (FST) in the stromal cells of basal cell carcinomas [29]. Interestingly, our data showed that FST-like 1 expression accompanied GREM1 expression in the skin of recurrent incisional hernia patients. The findings in the literature support a role for GREMI in fibrosis of the skin and kidney and are suggestive of a role in hernia formation. The 
Differential gene expression of selected genes by PCR array

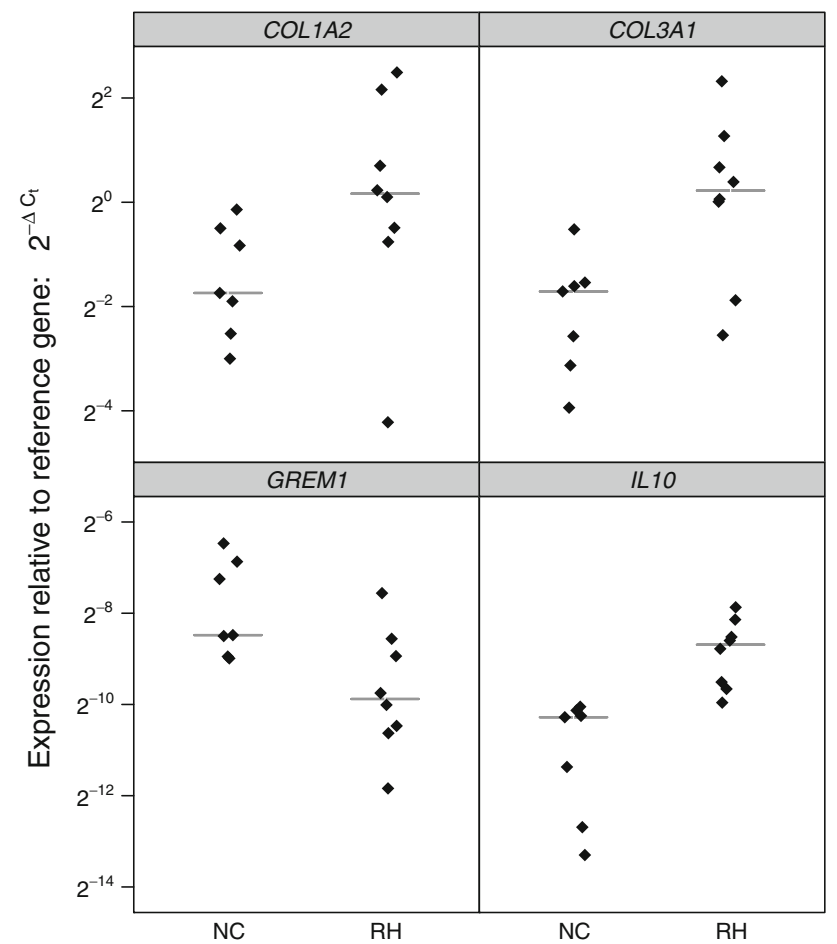

Fig. 2 Patient-level gene expression data for 4 selected genes from PCR array with group median indicated by a horizontal line

potential role of GREMI becomes further substantiated when viewed from a perspective that defects in normal wound healing and mechanical strain are frequently cited as causes of hernia formation and recurrence. Although our microarray data were validated by $\mathrm{qPCR}$ and PCR array, we are in the process of further testing the role of GREMI in an expanded population of patients.

More conventional genes of interest from our study were the 8 genes directly involved with collagen synthesis and those associated with hernia formation, Ehlers-Danlos syndrome, and Marfan's syndrome such as FBN1. Our data on COLIA1 and COL3A1 were validated by qPCR and PCR array. The ratio of collagen I to collagen III decreased in the $\mathrm{RH}$ patients in comparison with $\mathrm{NC}$ as would be expected according to the literature [4-8]. These data are strengthened by the fact that a decrease was seen regardless of which collagen 1 alpha chain was analyzed. The clinical manifestations of Marfan's suggest that alterations in connective tissue stability may play an important role. Mutations in FBN1 are known to cause Marfan's syndrome and have been associated with tissue stability [30]. Recently, an immunohistochemcial study was performed on scar and nonscar regions of human skin and fascia [30]. The authors studied 22 patients who underwent repeated laparotomy: 12 had developed incisional hernia and $10 \mathrm{did}$

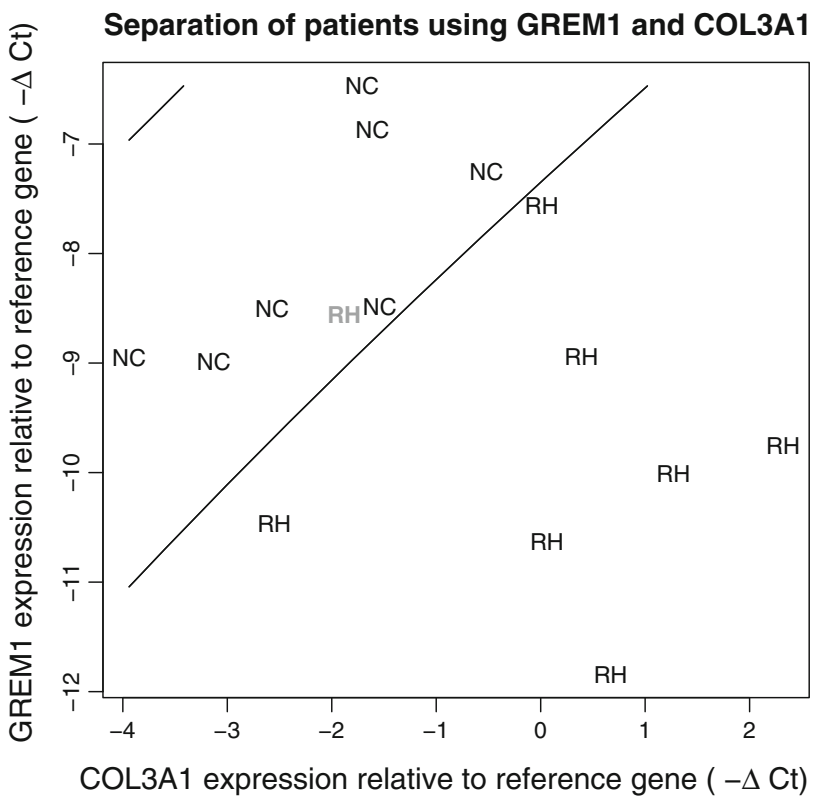

Fig. 3 Ability of the combination of GREM1 and COL3A1 gene expression to separate $\mathrm{RH}$ and $\mathrm{NC}$ patients. PCR array data were used to explore the utility of gene expression of GREM1 and COL3A1 as markers to distinguish $\mathrm{RH}$ and $\mathrm{NC}$ patients. The best separation boundary (solid line) was determined using quadratic discriminant analysis. Using all of the data, only 1 patient ( $\mathrm{RH}$, gray) was misclassified (93\% accuracy). Using leave-one-out cross-validation, in which each patient's data is held out (in turn) during the calculation of the best boundary and subsequently evaluated for accuracy, 13/15 (86\%) patients were correctly classified

not and were used as control. They found that FBN1 may be an important contributing factor to tissue stability and incisional hernia formation [30].

Although the size of our study may be viewed as a potential limitation, it is important to emphasize that this was a limited pilot study to assess the feasibility of whether recurrent incisional hernia formation is due to differing gene expression profiles that alter wound healing. The statistical power generated from a larger study that could incorporate adjustments for demographic variables should further substantiate our results. These data would be used to enhance our knowledge of the molecular biology of hernia formation and wound healing. In addition, the gene expression profiles would have both narrow and broad ramifications. For instance, they could predict which ventral hernia patients might be more likely to recur, and potentially offer targeted, patient-specific therapies for the prevention of recurrent incisional hernia such as type of mesh and repair method. A limited investigation of this possibility showed that the combination of GREMI and COL3A1 have potential in this regard (Fig. 3). It is not surprising, since COL1A2, COL3A1, GREM1, and ILIO all show promise as biomarkers (either individually or more powerfully in the form of a panel) due to the minimal 
overlap in the $\mathrm{RH}$ and $\mathrm{NC}$ groups for each of these genes (Fig. 2). From a broader vantage point, however, profiles could be generated from a preoperative assay that would also stratify patients into low- and high-risk populations of prospective hernia formers or poor wound healers. Ultimately, this would lead to the development of rapid and standardized wound-healing methods providing minimal or no postoperative complications.

\section{Conclusion}

In summary, using microarray analysis, we have performed for the first time a genome-wide pilot study of patients who have recurrent incisional hernias. We have identified distinct gene expression profiles in these patients and have furthered our understanding of recurrent incisional hernia formation. Moreover, we have found an association between a novel gene to the hernia literature, GREM1, and incisional hernia formation. To our knowledge, this is the first report to demonstrate such an association. Based upon our results, gene expression profiles may act as surrogate markers that stratify patients into different groups at risk for hernia development prior to their initial surgery. Further investigation using a larger patient population is planned to substantiate these results and potentially provide novel insights into hernia formation, wound healing, and ultimately targeted, patient-specific therapy.

Acknowledgments The project was supported by start-up funds from the University of Missouri as well as a Department of Surgery Internal Grant award.

Conflict of interest The authors declare that they have no competing interests.

Open Access This article is distributed under the terms of the Creative Commons Attribution License which permits any use, distribution, and reproduction in any medium, provided the original author(s) and the source are credited.

\section{References}

1. Millikan KW (2003) Incisional hernia repair. Surg Clin N Am $83: 1223-1234$

2. Awad ZT, Puri V, LeBlanc K, Stoppa R, Fitzgibbons RJ Jr, Iqbal A, Filipi CJ (2005) Mechanisms of ventral hernia recurrence after mesh repair and a new proposed classification. J Am Coll Surg 201:132-140

3. Franz MG (2006) The biology of hernias and the abdominal wall. Hernia 10:462-471

4. Klinge U, Zheng H, Si ZY, Schumpelick V, Bhardwaj R, Klosterhalfen B (1999) Synthesis of type I and III collagen, expression of fibronectin and matrix metalloproteinases-1 and -13 in hernial sac of patients with inguinal hernia. Int J Surg Investig 1:219-227
5. Klinge U, Zheng H, Si Z, Schumpelick V, Bhardwaj RS, Muys L, Klosterhalfen B (1999) Expression of the extracellular matrix proteins collagen I, collagen III and fibronectin and matrix metalloproteinase- 1 and -13 in the skin of patients with inguinal hernia. Eur Surg Res 31:480-490

6. Klinge U, Si ZY, Zheng H, Schumpelick V, Bhardwaj RS, Klosterhalfen B (2000) Abnormal collagen I to III distribution in the skin of patients with incisional hernia. Eur Surg Res 32:43-48

7. Rosch R, Junge K, Knops M, Lynen P, Klinge U, Schumpelick V (2003) Analysis of collagen-interacting proteins in patients with incisional hernias. Langenbecks Arch Surg 387:427-432

8. White B, Osier C, Gletsu N, Jeansonne L, Baghai M, Sherman M, Smith CD, Ramshaw B, Lin E (2007) Abnormal primary tissue collagen composition in the skin of recurrent incisional hernia patients. Am Surg 73:1254-1258

9. Liem MS, van der Graaf Y, Beemer FA, van Vroonhoven TJ (1997) Increased risk for inguinal hernia in patients with EhlersDanlos syndrome. Surgery 122:114-115

10. Rowe DW, Shapiro JR, Poirier M, Schlesinger S (1985) Diminished type I collagen synthesis and reduced alpha 1(I) collagen messenger RNA in cultured fibroblasts from patients with dominantly inherited (type I) osteogenesis imperfecta. J Clin Invest 76:604-611

11. Deak SB, Ricotta JJ, Mariani TJ, Deak ST, Zatina MA, Mackenzie JW, Boyd CD (1992) Abnormalities in the biosynthesis of type III procollagen in cultured skin fibroblasts from two patients with multiple aneurysms. Matrix 12:92-100

12. Heath JD, Cox D, Goralski T, Retief J (2007) NuGen's WTOvation FFPE System coupled with a novel labeling protocol enables genome-wide gene expression profiling of FFPE sample on the Illumina BeadArray platform. Application Note \#2. NuGen Technologies

13. Calaluce R, Gubin MM, Davis JW, Magee JD, Chen J, Kuwano Y, Gorospe M, Atasoy U (2010) The RNA binding protein HuR differentially regulates unique subsets of mRNAs in estrogen receptor negative and estrogen receptor positive breast cancer. BMC Cancer 10:126-140

14. Smyth GK (2004) Linear models and empirical bayes methods for assessing differential expression in microarray experiments. Stat Appl Genet Mol Biol 3:Article3

15. Ramos-Vara JA, Beissenherz ME (2000) Optimization of immunohistochemical methods using two different antigen retrieval methods on formalin-fixed paraffin-embedded tissues: experience with 63 markers. J Vet Diagn Invest 12:307-311

16. Gubin MM, Calaluce R, Davis JW, Magee JD, Strouse CS, Shaw DP, Ma L, Brown A, Hoffman T, Rold TL, Atasoy U (2010) Overexpression of the RNA binding protein HuR impairs tumor growth in triple negative breast cancer associated with deficient angiogenesis. Cell Cycle 9:3337-3346

17. Pelch KE, Schroder AL, Kimball PA, Sharpe-Timms KL, Davis JW, Nagel SC (2010) Aberrant gene expression profile in a mouse model of endometriosis mirrors that observed in women. Fertil Steril 93:1615-1627, e1817

18. Benjamini Y, Hochberg Y (1995) Controlling the false discovery rate: a practical and powerful approach to multiple testing. J R Stat Soc B 57:289-300

19. Avsian-Kretchmer O, Hsueh AJ (2004) Comparative genomic analysis of the eight-membered ring cystine knot-containing bone morphogenetic protein antagonists. Mol Endocrinol 18:1-12

20. Bucknall TE, Cox PJ, Ellis H (1982) Burst abdomen and incisional hernia: a prospective study of 1129 major laparotomies. $\mathrm{Br}$ Med J (Clin Res Ed) 284:931-933

21. Greenall MJ, Evans M, Pollock AV (1980) Midline or transverse laparotomy? A random controlled clinical trial. Part I: Influence on healing. Br J Surg 67:188-190 
22. Gys T, Hubens A (1989) A prospective comparative clinical study between monofilament absorbable and non-absorbable sutures for abdominal wall closure. Acta Chir Belg 89:265-270

23. Hsu DR, Economides AN, Wang X, Eimon PM, Harland RM (1998) The Xenopus dorsalizing factor Gremlin identifies a novel family of secreted proteins that antagonize BMP activities. Mol Cell 1:673-683

24. Topol LZ, Modi WS, Koochekpour S, Blair DG (2000) DRM/ GREMLIN (CKTSF1B1) maps to human chromosome 15 and is highly expressed in adult and fetal brain. Cytogenet Cell Genet 89:79-84

25. McMahon R, Murphy M, Clarkson M, Taal M, Mackenzie HS, Godson C, Martin F, Brady HR (2000) IHG-2, a mesangial cell gene induced by high glucose, is human gremlin. Regulation by extracellular glucose concentration, cyclic mechanical strain, and transforming growth factor-beta1. J Biol Chem 275:9901-9904

26. Lappin DW, McMahon R, Murphy M, Brady HR (2002) Gremlin: an example of the re-emergence of developmental programmes in diabetic nephropathy. Nephrol Dial Transpl 17(Suppl 9):65-67
27. Murphy M, McMahon R, Lappin DW, Brady HR (2002) Gremlins: is this what renal fibrogenesis has come to? Exp Nephrol 10:241-244

28. Meyringer R, Neumann E, Judex M, Landthaler M, Kullmann F, Scholmerich J, Gay S, Tarner IH, Distler O, Muller-Ladner U (2007) Analysis of gene expression patterns in systemic sclerosis fibroblasts using RNA arbitrarily primed-polymerase chain reaction for differential display. J Rheumatol 34:747-753

29. Sneddon JB, Zhen HH, Montgomery K, van de Rijn M, Tward $\mathrm{AD}$, West R, Gladstone H, Chang HY, Morganroth GS, Oro AE et al (2006) Bone morphogenetic protein antagonist gremlin 1 is widely expressed by cancer-associated stromal cells and can promote tumor cell proliferation. Proc Natl Acad Sci USA 103:14842-14847

30. Fricke M, Langer C, Brunner E, Sakai LY, Fuzesi L, Reinhardt DP, Quondamatteo F (2008) Fibrillin-1 in incisional hernias: an immunohistochemical study in scar and non-scar regions of human skin and muscle fasciae. J Anat 212:674-685 